\title{
Fibro-histiocitoma maligno da pálpebra: relato de caso
}

\author{
Malignant fibrous histiocytoma of the eyelid: case report
}

\author{
Ana Carolina Toledo Dias ${ }^{1}$ \\ Luciano de Sousa Pereira ${ }^{2}$ \\ Lílian Midori Sameshima ${ }^{3}$ \\ Frederico Augusto Costa Reis ${ }^{4}$ \\ José Vital Filhos
}

\section{RESUMO}

Os fibro-histiocitomas representam $1 \%$ das massas orbitárias e podem ser histologicamente classificados em benignos, localmente agressivos e malignos - os últimos representando aproximadamente $11 \%$ do total. Nesse estudo, os autores descrevem um caso raro de fibro-histiocitoma maligno de pálpebra, ressaltando as características clínicas e histopatológicas desta neoplasia.

Descritores: Histiocitoma fibroso maligno/diagnóstico; Neoplasias palpebrais; Procedimentos cirúrgicos oftalmológicos; Radioterapia adjuvante; Humano; Masculino; Adulto; Relato de casos [Tipo de publicação]

\section{INTRODUÇÃO}

Fibro-histiocitoma é o termo aplicado a um grupo de tumores mesenquimais que envolvem principalmente músculos esqueléticos, fáscias e tecidos adiposos das extremidades e do retroperitônio. Como esses elementos tissulares estão presentes na órbita, é de se supor que esta região anatômica possa ser acometida pelo tumor ${ }^{(1)}$, embora virtualmente quaisquer partes dos tecidos moles possam estar envolvidas ${ }^{(2)}$. Apesar de os fibrohistiocitomas serem os tumores mesenquimais primários mais frequentes da órbita dos adultos, representam apenas $1 \%$ das massas orbitárias ${ }^{(1,3-4)}$. A presença deste tipo de tumor é ainda mais rara na conjuntiva, episclera e saco lacrimal e o acometimento palpebral seguramente é o mais incomum. Existem apenas 4 casos de fibro-histiocitoma com localização palpebral descritos na literatura ${ }^{(5-6)}$.

De acordo com os achados histológicos, são classificados em benignos, localmente agressivos e malignos; os últimos constituem, aproximadamente, $11 \%$ do total ${ }^{(1)}$. A média de idade dos pacientes acometidos é 43 anos, variando de 4 a 85 anos, e, aparentemente, não há predileção por sexo ${ }^{(1)}$. É muito raro em crianças e, quando ocorre, há predomínio no sexo masculino ${ }^{(7)}$.

Os sinais e sintomas mais comuns são proptose, presença de massa, diminuição da visão, diplopia e dor; menos comumente podem ocorrer edema de pálpebras e conjuntiva, lacrimejamento, ptose palpebral, paralisia de músculos extraoculares e papiledema ${ }^{(1)}$.

As manifestações clínicas, radiológicas e histológicas são variáveis e o diagnóstico pode ser difícil, na maioria das vezes dependendo do estudo imuno-histoquímico para ser concluído ${ }^{(4)}$.

O objetivo do presente trabalho foi relatar um caso de fibrohistiocitoma maligno da pálpebra e ressaltar as características clínicas e histopatológicas desta neoplasia.

\section{RELATO DO CASO}

Paciente de 43 anos, sexo masculino, natural e procedente de São Paulo, apresentou tumoração arredondada na região temporal superior da pálpebra 
superior direita, de rápido crescimento, há quatro meses. Negava trauma. À ectoscopia, observava-se massa arredondada de consistência fibro-elástica, medindo aproximadamente $2,5 \mathrm{~cm}$ de diâmetro, bem delimitada, não aderida a planos profundos, indolor e sem sinais flogísticos. Ao exame oftalmológico apresentava acuidade visual corrigida de 20/20 e J1 em ambos os olhos, biomicroscopia, fundoscopia e tonometria sem alterações. A tomografia computadorizada de órbita revelou lesão aparentemente sólida, de contornos regulares, não infiltrativa.

Optou-se por biópsia excisional, sendo a lesão retirada sem dificuldade, não havendo aderência aos tecidos adjacentes. A massa era bem delimitada, lobulada e com coloração branco-amarelada. O exame anatomopatológico levantou suspeita de sarcoma fusocelular de alto índice mitótico. Realizou-se, então, o estudo imuno-histoquímico, com positividade para os antígenos Vimentina, Ki67, CD68, e negatividade para PS100, Desmina, Actina e CD34. Este perfil definiu o diagnóstico de fibro-histiocitoma maligno. O estadiamento para tumores não identificou metástases.

\section{DISCUSSÃO}

O paciente em questão possuía 43 anos de idade, o que coincide com a média de idade de aparecimento desta enfermidade ${ }^{(7)}$.

O fibro-histiocitoma palpebral pode apresentar associação com história de trauma em $9 \%$ dos casos, tendo sido descrito após pequenos traumas como picadas de insetos ${ }^{(1)}$. É relatada, ainda, a possibilidade de surgimento de fibro-histiocitoma como tumor secundário ao tratamento radioterápico por retinoblastoma, fibrosarcoma ou osteosarcoma ${ }^{(1,7-8)}$. Entretanto, o paciente em questão negava estas possibilidades.

Os tumores são classificados como benignos, localmente agressivos e malignos ${ }^{(1)}$. Com relação ao aspecto macroscópico, os tumores benignos são menores (tamanho médio de $2,7 \mathrm{~cm}$ ), coincidindo com o tumor aqui descrito e contrastando com os malignos (média de $5,5 \mathrm{~cm}$ ). Os localmente agressivos são de tamanho intermediário (média de $3,2 \mathrm{~cm}$ ) ${ }^{(1)}$.

Usualmente são massas lobuladas branco-acinzentadas ou amareladas, ocasionalmente com áreas císticas ou hemorrágicas e, raramente, áreas com aspecto mucóide ${ }^{(1)}$.

Os tumores benignos são habitualmente circunscritos e, ocasionalmente, verdadeiramente encapsulados, enquanto os malignos costumam apresentar margens infiltradas. Segundo este padrão, o tumor aqui relatado apresentava características de benignidade. Um pequeno número de tumores malignos e localmente agressivos pode parecer bem delimitado, mas um exame histológico cuidadoso geralmente evidencia um caráter infiltrativo ${ }^{(1)}$.

O padrão histológico é composto por uma população celular bifásica, com fibroblastos celulares fusiformes alongados que produzem colágeno, associados a componente histiocítico mono e multinucleado que, presumivelmente, origina-se de uma célula mãe fibroblástica estromal facultativa e multipotencial ${ }^{(3)}$.
Alguns tumores têm predomínio histiocítico, outros predomínio fibroblástico e outros, uma mistura de ambos ${ }^{(7,9-10)}$. O arranjo das células fusiformes em padrão vorticilar ou de roda dentada é um dos critérios diagnósticos ${ }^{(8,4,11)}$.

O período de evolução dos sintomas tende a ser maior nos tumores benignos (média de 31 meses), do que nos malignos (média de 3,4 meses), com período intermediário (média de 21 meses) nos localmente agressivo ${ }^{(1)}$. Embora teoricamente pareça existir uma correlação entre o tempo de evolução e o tamanho da lesão para tentar estabelecer um critério de benignidade ou malignidade ${ }^{(1)}$, nem sempre isso ocorre. No caso descrito, o paciente apresentava uma lesão de tamanho pequeno e bem delimitada (característica de benignidade), porém, com rápida evolução (característica de malignidade), dois dados aparentemente discrepantes, mas possíveis quando se trata de fibro-histiocitoma.

Em um estudo com tomografias computadorizadas de dez casos de fibro-histiocitoma orbitário, observaram-se lesões com limites bem definidos, arredondados, lobulados ou alongados, que se realçavam após a injeção de contraste, ficando na maioria dos casos com isodensidade em relação ao cérebro. Dentre os dez casos, quatro apresentavam localização intraconal, três extraconais, duas em ambos os compartimentos e, em um caso, apenas o comprometimento de um único músculo extraocular (sem preferência por quadrante) $)^{(4)}$. Alguns autores descreveram que a porção superonasal é a localização orbitária mais frequente e com extensão para os seios paranasais em $6 \%$ dos $\operatorname{casos}^{(1)}$. A discrepância dos achados provavelmente se deve à diferença do tamanho das amostras. Porém, como os achados tomográficos são inespecíficos (alguns benignos podem ter aspecto infiltrativo e alguns malignos podem ser bem delimitados - como no caso descrito), há a concordância de que o objetivo da tomografia computadorizada, da mesma forma que o da ressonância magnética, é identificar o local e a extensão da lesão, assim como definir a indicação de biópsia e/ou excisão ${ }^{(4,8)}$.

Fazem parte do diagnóstico diferencial: fibromatoses, fasceíte nodular, fibrossarcoma, neurilemoma, neurofibroma, schwanoma, meningioma, tumor fibroso solitário, linfoma, histiocitose sistêmica e metástase $e^{(1,8-9,12-13)}$. Quando a lesão acomete a pálpebra, tem como diagnóstico diferencial: calázio, adenoma e carcinoma de células sebáceas. Sendo assim, lesões frequentes e de comportamento aparentemente benigno, não devem deixar de ser analisadas quanto a seu aspecto histológico, evitando-se dessa forma o diagnóstico errôneo ${ }^{(14-15)}$. A presença de fibro-histiocitoma associado a melanoma maligno de coróide também já foi descrita, devendo-se atentar a isso, apesar da raridade, no exame primário dos portadores de algum dos dois tipos tumorais ${ }^{(16)}$. Aproximadamente um terço dos tumores são vascularizados, podendo conter focos de hemorragia e fazem diagnóstico diferencial com o hemangioma e, se durante a ressecção da lesão houver ruptura, pode ser difícil fazer a diferenciação de hemangiopericitoma, hemangioendotelioma e angiossarcoma ${ }^{(1,17-18)}$. As variantes mixóides podem ser confundidas com mixoma e 
lipossarcoma mixóide. Já as variantes pleomórficas podem ser diferenciadas de lipossarcoma pleomórfico, rabdomiossarcoma pleomórfico, carcinoma pleomórfico, fibroxantoma atípico e doença de Hodgkin ${ }^{(1)}$. Os tumores que fazem diagnóstico diferencial na infância são o rabdomiossarcoma, o xantogranuloma orbitário e a histiocitose de células de Langerhans $^{(3)}$.

A pedra angular para o diagnóstico é o estudo do perfil imuno-histoquímico com positividade para o antígeno vimentina e, às vezes, para actina ou alfa 1 antitripsina e negatividade para desmina, queratina, antígenos de membrana epitelial, proteína S100, antígeno relacionado ao fator VIII, CD34 e antígeno carcinoembriônico ${ }^{(3,8,10)}$. O paciente deste relato apresentava exame com alto índice mitótico e positividade para os antígenos vimentina, Ki67, CD68, e negatividade para PS100, desmina, actina e CD34, compatível com o diagnóstico de fibro-histiocitoma maligno.

O diagnóstico de fibro-histiocitoma maligno tem implicações importantes no tratamento. Outros autores observaram que, em tumores mesenquimais malignos, margens positivas aproximadamente dobram o risco de recidiva local, metástases, e morte relacionada ao tumor ${ }^{(19)}$. Em outro estudo, margens cirúrgicas negativas associaram-se a menor taxa de recidiva e maior sobrevida ${ }^{(20)}$. Radioterapia adjuvante para o tratamento de tumores mesenquimais malignos parece estar relacionado com menor taxa de recidiva local ou metástases quando comparado ao tratamento cirúrgico isoladamente ${ }^{(20-21)}$, especialmente em casos com margens cirúrgicas comprometidas $^{(20)}$. O uso de quimioterapia adjuvante no tratamento de sarcomas de extremidades pode trazer beneficio com relação a sobrevida e taxa de recidiva ${ }^{(22-23)}$, no entanto, a escassez de estudos não nos permite chegar a mesma conclusão com relação ao tratamento do fibro-histiocitoma maligno periocular. A quimioterapia, nesses casos, fica restrita aos casos mais infiltrados, nos quais o risco de recidiva local e/ou metástases justificam o seu uso. Devido à baixa incidência de comprometimento de linfonodos, inicialmente não é indicado o esvaziamento ganglionar ${ }^{(9)}$.

Em tumores malignos existe, em alguns casos, a opção de uma conduta conservadora, quando realizada a exérese completa do tumor (margens cirúrgicas livres). Sugere-se, porém, um seguimento clínico e radiológico cuidadoso, com atenção especial aos pulmões e ao sistema nervoso central. Sinais de recidiva podem não ocorrer, mas não se deve descartar a possibilidade de exenteração orbitária, caso isto ocorra ${ }^{(9,21)}$. Até o momento, a biópsia excisional com remoção completa da lesão foi a conduta adotada no caso aqui descrito, levando-se em conta que a lesão era pequena e bem delimitada. De acordo com a evolução, pode-se ainda definir a necessidade de radio e/ou quimioterapia.

Com 150 casos descritos, foi relatada a sobrevida de dez anos de $100 \%$ para os portadores de lesões benignas, com recorrência do tumor em $31 \%{ }^{(1)}$. Nos localmente agressivos houve recorrência em $57 \%$ dos casos, e a taxa de sobrevida de cinco anos foi de $100 \%$ e a de dez anos, de $92 \%$ (morte por transformação maligna com invasão intracranial, sem metástases). Já, nos malignos, a recorrência ocorreu em 64\% dos casos e a sobrevida de cinco anos foi de $54 \%$ e a de dez anos, apenas $23 \%{ }^{(1)}$.

Concluindo, por ser o fibro-histiocitoma uma doença rara, apresentar características pouco específicas do ponto de vista clínico e ter evolução potencialmente maligna, deve-se sempre lançar mão de recursos específicos como a imunohistoquímica para o seu diagnóstico correto e rápido. Desta forma uma conduta menos agressiva pode ser adotada, preservando o paciente do risco de exenteração, mesmo nos casos em que o tumor apresenta características de maior malignidade. Entretanto, deve-se ter em mente que o paciente deve ser acompanhado de forma periódica para o resto da vida.

\section{ABSTRACT}

Fibrous histiocytomas represent $1 \%$ of all orbital masses and may be classified into benign, locally aggressive and malignant - these representing nearly $11 \%$ of the total. In this study, the authors describe an unusual case of malignant fibrous histiocytoma of the eyelid, discussing clinical and histological features of this neoplasm.

Keywords: Histiocytoma, malignant fibrous/diagnosis; Eyelid neoplasms; Ophthalmic surgical procedures; Radiotherapy adjuvant; Human; Male; Adult; Case reports [Publication type]

\section{REFERÊNCIAS}

1. Font RL, Hidayat AA. Fibrous histiocytoma of the orbit. A clinicopathologic study of 150 cases. Hum Pathol. 1982;13(3):199-209.

2. Azevedo ML, Cardoso PJ. Fibro-histiocitoma orbitário: apresentação de caso com estudo histopatológico. Rev Bras Oftalmol 1986;45(6):22-6.

3. Blanco AO, Canales JL, Castañeda NA, Reyes AR, Tovilla y Pomar JL. [Fibrohistiocitoma orbitário: reporte de un caso y revisión de la literatura]. Rev Mex Oftalmol. 2001;75(2):40-5. Spanish.

4. Jacomb-Hood J, Moseley IF. Orbital fibrous histiocytoma: computed tomography in 10 cases and a review of radiological findings. Clin Radiol. 1991; 43(2):117-20.

5. Jordan DR, Addison DJ, Anderson RL. Fibrous histiocytoma, an uncommon eyelid lesion. Arch Ophthalmol. 1989;107(10):1530-1.

6. Rossi P, Ducasse A, Pluot M, Brugniart C, Gotzamanis A, Jouhaud F. [Malignant fibrous histiocytoma of the eyelid]. J Fr Ophtalmol. 2002;25(10): 1036-42. French.

7. Cole CH, Magee JF, Gianoulis M, Rogers PC. Malignant fibrous histiocytoma in childhood. Cancer. 1993;71(12):4077-83.

8. Dalley RW. Fibrous histiocytoma and fibrous tissue tumors of the orbit. Radiol Clin North Am. 1999;37(1):185-94.

9. Monteiro ML, Usuba FS, Sampaio CM, Bignardi TH. Fibrohistiocitoma maligno da órbita. Rev Bras Oftalmol. 1994;53(5):60-3.

10. Choi G, Lee U, Won NH. Fibrous histiocytoma of the lacrimal sac. Head Neck. 1997;19(1):72-5.

11. Ulloa TK, Anderson SF. Orbital fibrous histiocytoma: case report and literature review. J Am Optom Assoc. 1999;70(4):253-60.

12. Marback RL, Kincaid MC, Green WR, Iliff WJ. Fibrous histiocytoma of the lacrimal sac. Am J Ophthalmol. 1982;93(4):511-7.

13. Ing EB, Kennerdell JS, Olson PR, Ogino S, Rothfus WE. Solitary fibrous tumor of the orbit. Ophthal Plast Reconstr Surg. 1998;14(1):57-61.

14. Jakobiec FA, DeVoe AG, Boyd J. Fibrous histiocytoma of the tarsus. Am J Ophthalmol. 1977;84(6):794-7. 
15. DeStafeno JJ, Carlson JA, Meyer DR. Solitary spindle-cell xanthogranuloma of the eyelid. Ophthalmology. 2002;109(2):258-61.

16. Calugaru M, Barsu M, Rotaru A, Ciuce C. Two different primary ophthalmic cancers in a 39-year-old female patient. Oftalmologia. 1994;38(3):205-15.

17. Khong JJ, Chen CS, James CL, Huilgol SC, O'Donnel BA, Sullivan TJ, et al. Malignant fibrous histiocytoma of the eyelid: differential diagnosis and management. Ophthal Plast Reconstr Surg. 2005;21(2):103-8.

18. Nath R, Saxena S, Agarwal PK, Roy S. Angiomatoid malignant fibrous histiocytoma of the eyelid. Indian J Ophthalmol. 1992;40(2):63-5.

19. Stojadinovic A, Leung DH, Hoos A, Jacques DP, Lewis JJ, Brennan MF. Analysis of the prognostic significance of microscopic margins in 2,084 localized primary adult soft tissue sarcomas. Ann Surg. 2002;235(3):424:34 Comment in: Curr Surg. 2003;60(1):20-4
20. Betal A, Kandil A, Allam A, Khafaga Y, El-Husseiny G, El-Enbaby A, et al. Malignant fibrous histiocytoma: a retrospective study of 109 cases. Am J Clin Oncol. 2002;25(1):16-22.

21. Wilson RB, Crowe PJ, Fisher R, Hook C, Donnellan MJ. Extremity soft tissue sarcomas: factors predictive of local recurrence and survival. Aust N Z J Surg. 1999;69(5):344-9.

22. Henshaw RM, Priebat DA, Perry DJ, Shomookler BM, Malawer MM. Survival after induction chemotherapy and surgical resection for high grade soft tissue sarcoma. Is radiation necessary? Ann Surg Oncol. 2001;8(6):484-95.

23. Frustaci S, Gherlinzoni F, De Paoli A, Bonetti M, Azzarelli A, Comandone A, et al. Adjuvant chemotherapy for soft tissue sarcomas of the extremiries and girdles: results of the Italian randomized cooperative trial. J Clin Oncol. 2001;19(5):1238-47. Comment in: J Clin Oncol. 2001;19(5):1235-7.

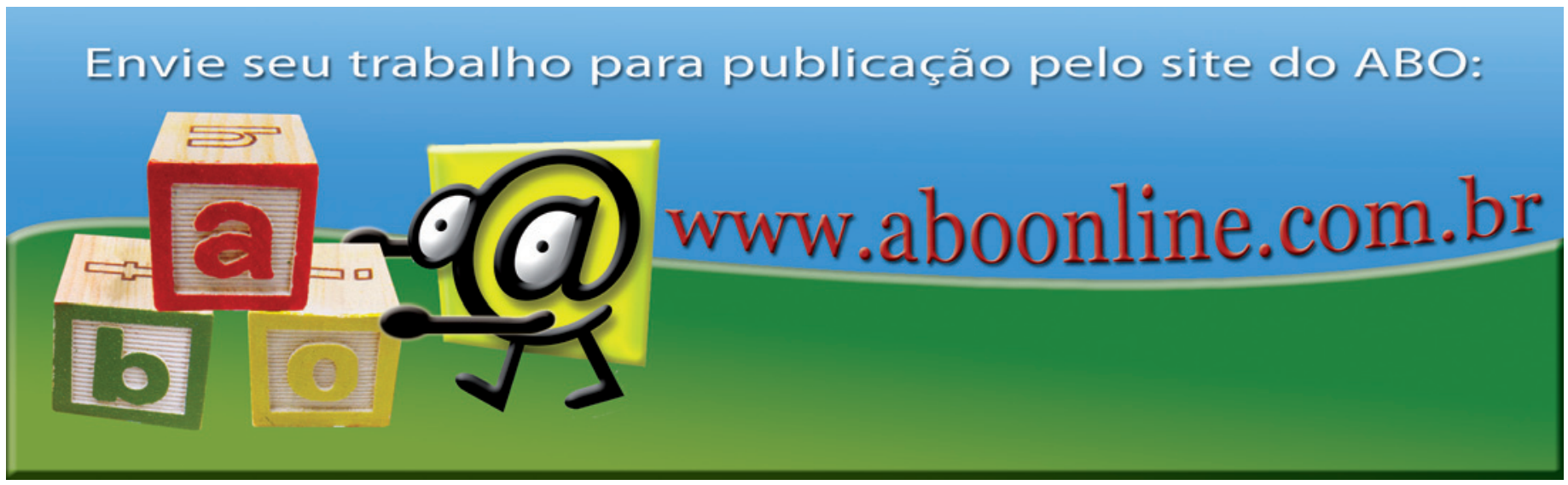

